\title{
Experimental study of water droplet break up in water in oil dispersions using an apparatus that produces localized pressure drops
}

\author{
Fabricio S. Silva ${ }^{1,2,}{ }^{*}$, Ricardo A. Medronho ${ }^{2}$, and Luiz Fernando Barca ${ }^{3}$ \\ ${ }^{1}$ PETROBRAS - Petróleo Brasileiro S. A., CENPES/PDDP/TPP, Av. Horácio Macedo 950, Cidade Universitária, \\ Ilha do Fundão, 21941-915 Rio de Janeiro, RJ, Brazil \\ ${ }^{2}$ UFRJ - Universidade Federal do Rio de Janeiro, Escola de Química, Av. Athos da Silveira Ramos 149, Cidade Universitária, \\ Ilha do Fundão, 21941-909 Rio de Janeiro, RJ, Brazil \\ ${ }^{3}$ UNIFEI - NUSEC - Núcleo de Separadores Compactos, Instituto de Engenharia Mecânica, Av. BPS 1303, \\ 37500-903 Itajubá, MG, Brazil
}

Received: 17 July 2018 / Accepted: 22 October 2018

\begin{abstract}
Oil production facilities have choke/control valves to control production and protect downstream equipment against over pressurization. This process is responsible for droplets break up and the formation of emulsions which are difficult to treat. An experimental study of water in oil dispersion droplets break up in localized pressure drop is presented. To accomplish that, an apparatus simulating a gate valve was constructed. Droplet Size Distribution (DSD) was measured by laser light scattering. Oil physical properties were controlled and three different break up models were compared with the experimental results. All experimental maximum diameters $\left(d_{\max }\right)$ were above Kolmogorov length scale. The results show that $d_{\max }$ decreases with increase of energy dissipation rate $(\varepsilon)$ according to the relation $d_{\max } \propto \varepsilon^{-0.42}$. The Hinze $(1955$, AIChE J. 1, 3, 289-295) model failed to predict the experimental results, although, it was able to adjust reasonably well those points when the original proportional constant was changed. It was observed that increasing the dispersed phase concentration increases $d_{\max }$ due to turbulence suppression and/or coalescence phenomenon. Turbulent viscous break up model gave fairly good prediction.
\end{abstract}

\section{Introduction}

The primary oil processing in a production facility aims at promoting produced fluids separation (oil, gas, brine and eventually solid sediments), in a way that the different phases can be obtained with a suitable purity for subsequent handling (Arnold and Stewart, 1999; Manning and Thompson, 1995). In the beginning of field exploitation, the production is basically oil and gas. Over the years, the oil field starts to produce an increasing amount of salty water. This brine can be connate water or be due processes of enhanced oil recovery (injection of seawater or produced water in the reservoir).

When the produced mixture reaches an offshore facility, it encounters a device called choke valve. Its function is to regulate the flow coming from the well and control its flux to guarantee an efficient yield, avoiding premature water production (Janssen et al., 2001). Another function of this valve is the protection of downstream equipment,

\footnotetext{
* Corresponding author: fabriciosoares@petrobras.com.br
}

by applying a pressure drop to adjust the flow pressure from the well for the downstream first stage separator operational pressure (Arnold and Stewart, 1999). Hence, this localized pressure drop promotes droplets break up since the flow energy is dissipated in a turbulent way. The result of this turbulent energy dissipation is stable dispersions or emulsions, which are very difficult to treat.

The design of separation stages and separators focuses in maximizing production and minimizing compressor horsepower (Arnold and Stewart, 1999; Manning and Thompson, 1995). It shall consider field characteristics, fluids properties, well flow pressure, temperature, Gas-Oil Ratio (GOR), particle diameter and other variables (Lockhart et al., 1987; Manning and Thompson, 1995). The higher number of stages, more light components will be stabilized in liquid phase (Arnold and Stewart, 1999; Lockhart et al., 1987). Subsequent stages operate in lower pressures, therefore, besides the pressure drop in the choke valve, there are pressure reductions between separation stages. Those pressure drops are fulfilled by control valves and, therefore, they are also drop break up generators. 
There are innumerous articles that study the break up phenomenon in pipe flows (Angelli and Hewitt, 2000; Kubie and Gardner, 1977; Simmons and Azzopardi, 2001). Other works studied this phenomenon in static mixers or rotor stator mixers (Grace, 1982; Lemenand et al., 2003; Rueger and Calabrese, 2013a, b).

Some studies tried to better understand droplet break up in flows passing through localized restrictions (Fossen and Schumann, 2016; Galinat et al., 2005; Janssen et al., 2001; Mitre et al., 2014; Paolinelli and Yao, 2017; van der Zande, 2000; van der Zande et al., 1998a, b, c, 1999a, b).

Most of the studies in this area were performed with low concentration of the dispersed phase (normally dispersions of oil in water) and/or with localized pressure drops below those observed in a production field. The experimental study, here presented, is inserted in the investigation of droplet break up in water in oil dispersions, with dispersed phase concentration varying between $5 \%$ and $10 \%$, and localized pressure drops varying from 3 to 9 bar.

\section{Theory}

A droplet in a dispersion is subjected to forces applied by the continuous phase that is surrounding the droplet (Hinze, 1955; Taylor, 1934).Thus, normal and tangential tensions deform the droplet surface (Lemenand et al., 2003). The force per area that opposes deformation, known as Laplace pressure $\left(P_{\mathrm{L}}\right)$, is proportional to the interfacial tension $(\sigma)$ and inversely proportional to the curvature radii of the interface $\left(R_{1}\right.$ and $\left.R_{2}\right)$, as shown in equation (1).

$$
P_{\mathrm{L}}=\sigma\left(\frac{1}{R_{1}}+\frac{1}{R_{2}}\right) \text {. }
$$

For spherical droplet, $R_{1}=R_{2}=d / 2$. From equations (1) and (2) can be written, where $d$ is the drop diameter:

$$
P_{\mathrm{L}}=\frac{4 \sigma}{d} .
$$

The third force per area acting in the drop deformation process and break up is related to the viscous tensions $(\sigma v)$ generated internally in the drop, by the external velocity gradient (continuous phase), which, according to Hinze (1955), can be described by the following expression, where $\mu_{\mathrm{d}}$ is the droplet viscosity, $\tau$ is an external tension and $\rho_{\mathrm{d}}$ is the droplet density:

$$
\sigma v=\frac{\mu_{\mathrm{d}}}{d} \sqrt{\frac{\tau}{\rho_{\mathrm{d}}}}
$$

The viscous tension and the interfacial tension of the droplet oppose the external tension in the break up process. Therefore, it is assumed that in order to have droplet break up, the external forces (imposed by continuous phase flow) must be greater than the sum of viscous and interfacial tensions (Hinze, 1955).

The dimensionless number of Weber (We - Eq. (4)) is the ratio between the deforming force per area applied by the continuous phase on the droplet and the interfacial tension that resists to this deformation. The higher the Weber number, higher will be the external tension compared to the internal tension. In a critical value of the Weber number $\left(\mathrm{We}_{\text {crit. }}\right)$, the droplet break up can occur (Hinze, 1955; Lemenand et al., 2003)

$$
\mathrm{We}=\frac{\tau_{\mathrm{d}}}{\sigma} .
$$

\subsection{Break up in a laminar flow}

Lemenand et al. (2003) have done a review of Taylor's $(1932,1934)$ study, which demonstrates that the droplets break up, in a laminar flow, is governed by viscous shear stress.

Following Walstra and Smulders (1998), when the external forces have origins in viscous stress, the Weber number assumes equation (5) form and can be named Capillary number, where $G$ is the droplet surrounding velocity gradient and $\mu_{\mathrm{c}}$ is the continuous phase viscosity:

$$
\mathrm{We}=\frac{G \mu_{\mathrm{c}} d}{\sigma} .
$$

The critical Weber number is dependent of the flow regime and phases viscosity ratio: $R_{\text {visc }}=\mu_{\mathrm{d}} / \mu_{\mathrm{c}}$, in which, for viscosity ratios bigger than approximately four $\left(R_{\mathrm{visc}} \sim 4\right)$, the droplets acts like a solid sphere and no break up can be observed. On the other hand, whenever $R_{\text {visc }}$ is close to zero (0.01 for example), a huge shear stress is required for droplet breaking up. To break a drop, a viscosity ratio between 0.1 and 1.0 is preferable (Grace, 1982; Lemenand et al., 2003; Walstra, 1993; Walstra and Smulders, 1998).

\subsection{Break up in a turbulent flow}

Kolmogorov and Hinze theories brought important knowledge to the study of droplet break up in a turbulent flow. This regime is characterized by the presence of eddies in various unpredictable directions, that constantly change by mutual interactions. It makes a turbulent local instantaneous velocity $(u)$ variation, in a chaotic way, leading to local velocity fluctuations $\left(u^{\prime}\right)$. The temporal mean of these fluctuations $\left(u^{\prime}\right)$ is equal to zero (Walstra, 1993).

A turbulent flow presents a large spectrum of eddies length $(\lambda)$. The bigger the vortices length, the higher are its $u^{\prime}$. These bigger eddies transfer kinetic energy to smaller ones that, nonetheless, presents higher velocity gradients. The velocity fluctuation for an eddy (with determined length) can be correlated with the energy dissipation rate per unit of mass $(\varepsilon)$, by equation (6) (Davies, 1985; Lemenand et al., 2003; Walstra, 1993; Walstra and Smulders, 1998):

$$
u^{\prime}=(\varepsilon \lambda)^{1 / 3} .
$$

The diameter of the smallest eddy is called Kolmogorov $\left(\lambda_{\mathrm{K}}\right)$ length-scale. Vortices smaller than $\lambda_{\mathrm{K}}$ are dissipated by the viscosity of the fluid, transforming the kinetic energy into heat. Eddies, bigger than Kolmogorov length-scale, are responsible for droplet break up (Walstra, 1993). The 
maximum stable droplet diameter $\left(d_{\max }\right)$ in an emulsion is determined by the equilibrium between the dynamic pressure generated by turbulent fluctuations, that tend to deform the drop, and the interfacial tension, that tends to keep the drop cohesive. Therefore, the Weber number assumes equation (7) form, where $\left\langle u^{\prime 2}\right\rangle$ is the mean value of the square of velocity, $\rho_{\mathrm{c}}$ is the continuous phase density and $d_{\max }$ is the maximum droplet diameter that resists to break up (Hinze, 1955; Lemenand et al., 2003).

$$
\mathrm{We}_{\text {crit }}=\frac{\rho_{c}<u^{\prime 2}>d_{\max }}{\sigma} .
$$

Hinze (1955) suggests that, in case of isotropic turbulence, the major contribution for the kinetic energy comes from fluctuations in the region of wave length where the Kolmogorov energy distribution is valid. Thus, $\left\langle u^{\prime 2}\right\rangle$ can be expressed as equation (8), where $C_{1}$ is a constant equivalent to 2, according to Batchelor (1951):

$$
<u^{\prime 2}>=C_{1}(\varepsilon d)^{2 / 3} .
$$

Hinze turbulent inertial break up model for predicting $d_{\max }$ is obtained from equations (7) and (8) (Eq. (9)). This model assumes that the dispersed fluid viscosity is negligible (Angelli and Hewitt, 2000; Davies, 1985; Hinze, 1955; Lemenand et al., 2003; Sleicher, 1962):

$$
d_{\max }=C \varepsilon^{-0.4} \sigma^{0.6} \rho_{c}^{-0.6} .
$$

Hinze (1955) applied this model to experimental tests of Clay $(1940 \mathrm{a}, \mathrm{b})$, considering $d_{95}=d_{\max }$, where $d_{95}$ is the diameter which $95 \%$ of the droplets lay below this value, and found that, for this case, the constant $C=0.725$, with standard deviation of 0.315 . This model was proposed for diluted dispersed systems. Clay's experimental tests were performed with dispersions in which the dispersed phase concentration was in the range from $0.9 \%$ to $4.8 \%$ (Paolinelli and Yao, 2017).

Hinze (1955) suggests that, when dispersed phase viscosity cannot be neglected, a viscosity group can be added to the model $\left(\mu_{\mathrm{d}} / \sqrt{ } \rho_{\mathrm{d}} \sigma d\right)$. Sleicher (1962) argued that the viscosity group suggested by Hinze is related to the natural frequency of vibration of droplets, and that this group is small and not relevant. Sleicher (1962), then, suggests that the important viscosity forces are the ones that oppose to the flow fields force, that elongate the droplet. The author indicates that this force per unit area should be proportional to $\mu_{\mathrm{d}} U / \sigma$, where $U$ is the mean pipe velocity.

After Hinze's work, innumerous papers investigating dispersions behavior, mainly of oil in water dispersions, were published. Davies (1985) correlated different types of devices with droplet diameters obtained from turbulent energy dissipation. In this study, a comparison of experimental tests and $d_{\text {max }}$ calculated by the Hinze's model (with typical energy dissipation for each device) showed good predictions. Differently that was defended by Sleicher (1962), Davies (1985) stated that, instead of mean pipe velocity, the turbulent fluctuation velocity $\left(u^{\prime}\right)$ that should be considered on viscosity term. By convenience, the author added the group $\mu_{\mathrm{d}} u^{\prime} / d_{\max }$ to the Laplace pressure term on Hinze's model. The new model proposed by Davies is presented in equation (10):

$$
d_{\max }=C_{\mathrm{d}}\left(\sigma+\frac{\mu_{\mathrm{d}} u^{\prime}}{4}\right)^{0.6} \rho_{c}^{-0.6} \varepsilon^{-0.4} .
$$

Both models, previously described, are valid for inertial sub-range and, therefore, consider only inertial forces dominating break-up phenomena $\left(\lambda_{\mathrm{K}}<d_{\max }<0.1\right.$ pipe diameter). It is expected that continuous phase viscosity do not have any influence. Walstra $(1983,1993)$ indicate some exceptions where the increase of continuous phase viscosity has influence in droplet size. In this case, some shear stress could be responsible to some of break-up occurring.

As stated before, Grace (1982) indicates that, for very small and very high viscosity ratios, droplet breakup due to shear flow is improbable. However, Stone (1994), affirms that the breakup under these conditions is possible if some vorticity is present in the flow. Moreover, Stone (1994) explained that abrupt changes of the flow type should also be responsible for droplet breakup due to droplet relaxation after deformation. This could occur when the apparatus geometry changes substantially.

Karbstein and Schubert (1995) also stated that is tough to produce emulsions of high viscosity ratios with simple shear flow. They affirm that in turbulent flow, the local fluctuating velocities are responsible droplet deformations, forming bulges and, therefore, causing droplet breakup. These local velocities fluctuations can also lead to droplet oscillations that could end up breaking the droplets.

Cristini et al. (2003) and Vankova et al. (2007) described a drop break up model in viscous turbulent flow (Sub-Kolmogorov regime). This model (Eq. (11)) was estimated by comparing viscous tensions with the droplet capillary pressure (Laplace pressure, Eq. (2)). The boundary condition for the validity of the viscous turbulent break up model is that the generated drop $\left(d_{\max v}\right)$ must be lower than the Kolmogorov length scale in turbulent flow. In Vankova et al. (2007) study, experimental tests were done to validate the model. In the continuous phase (water), some glycerin was added to enhance viscosity. Different levels of viscosity (18 $\mathrm{mPa} s$ max.) were tested and the dispersed phase was a mineral oil $(95 \mathrm{mPa}$ s):

$$
d_{\max v}=C_{v} \varepsilon^{-0,5} \mu_{\mathrm{c}}^{-0,5} \rho_{\mathrm{c}}^{-0,5} \sigma .
$$

The studies of Hinze (1955) and Davies (1985) were the precursors of innumerous other works in this area. Recently, some researchers started to evaluate droplet break up in restrictions (localized pressure drop). In a restriction, the flow passes through an intense turbulent region characterized by a high velocity zone with large velocity gradients, followed by a strong recirculation zone, where the energy dissipation is extremely high (Kwakernaak et al., 2007). The energy dissipation rate $(\dot{E})$ in a control volume is equal to the permanent difference of pressure $\left(\Delta P_{\text {perm }}\right)$ times the volume flowrate $(Q)$ (van der Zande, 2000). In a monophasic flow, the turbulent energy is dissipated into heat in a dissipation volume $\left(V_{\mathrm{dis}}\right)$. This volume can be expressed as an area $(S)$ times a dissipation length $(L)$, and the mass of fluid 
in dissipation zone is obtained multiplying this term by fluid density. Thus, the mean dissipation energy per unit mass can be calculated, as shown in equation (12) (Husveg et al., 2009; van der Zande, 2000):

$$
\varepsilon=\frac{\dot{E}}{\rho_{\mathrm{c}} S L}=\frac{\Delta P_{\mathrm{perm}} Q}{\rho_{\mathrm{c}} S L} .
$$

The energy dissipation calculus considers a dissipation volume or length. van der Zande et al. (1999a) defined that the dissipation zone extends as far as 2.5 times pipe diameter. In posterior work, van der Zande (2000) applying computational simulations observed that this dissipation zone could be higher, varying from 4.1 to 5.4 times pipe diameter. van der Zande et al. (1998c) argued about the possibility to have inhomogeneous energy dissipation rate downstream an orifice. In addition, considering recirculation zones as non-effective region for dissipation, the effective dissipation volume decreases.

In order to be valid, inertial turbulent break-up models based in Hinze theory indicate that the $d_{\max }$ obtained must be higher than the Kolmogorov length scale $\left(\lambda_{\mathrm{K}}\right)$, defined by equation (13) (where $v_{\mathrm{c}}$ is the kinematic viscosity of continuous phase), and below the higher eddies that are present in the flow $\left(\lambda_{\max }\right)$, equivalent to $10 \%$ of the pipe diameter (Paolinelli and Yao, 2017):

$$
\lambda_{\mathrm{K}}=\left(\frac{v_{c}{ }^{3}}{\varepsilon}\right)^{1 / 4} .
$$

Percy and Sleicher (1983) proposed a model (Eq. (14)) in which the fluid acceleration and, therefore, a pressure variation in the entrance of an orifice, is responsible for droplets break up. Their experiments were carried out with a low concentration organic dispersed phase in water as continuous phase, passing through different orifices. The term $d_{\mathrm{o}}$ is the orifice diameter:

$$
d_{\max }=C_{\mathrm{PS}}\left(\frac{d_{\mathrm{o}} \cdot \sigma}{\Delta P_{\max }}\right)^{1 / 2} .
$$

The constant $C_{\mathrm{PS}}$ that best fitted Percy and Sleicher experimental points was 3.1. van der Zande and van den Broek (1998b) fitted his experimental points in Percy and Sleicher model and the best adjust was obtained with constant equal to 5.4.

\section{Material and methods}

The experimental study was conducted in the Phase Separation Laboratory from Compact Separation Nucleus at Universidade Federal de Itajubá (UNIFEI).

This work was focused on the investigation of break up of water droplets dispersed in oil, when the flow passes through a restriction, which produces a localized pressure drop. The goal was to better understand water in oil emulsification when crude oil with residual produced water is submitted to pressure drops in petroleum primary process plants.
Table 1. Fluids physical properties at $20{ }^{\circ} \mathrm{C}$.

\begin{tabular}{lcrc}
\hline & $\begin{array}{c}\text { Dynamic viscosity } \\
(\mathrm{mPa} \mathrm{s})\end{array}$ & $\begin{array}{c}\text { Density } \\
\left(\mathrm{Kg} / \mathrm{m}^{3}\right)\end{array}$ & $\begin{array}{c}\text { Surface tension } \\
(\mathrm{mN} / \mathrm{m})\end{array}$ \\
\hline Mineral oil & 94.5 & 865.6 & 40.4 \\
Tap water & 1.0 & 1000.0 & 70.5 \\
\hline
\end{tabular}

\subsection{Fluids characterization}

The dispersions were obtained by mixing tap water with a commercial mineral oil (USP mineral oil). Water and oil physical properties were evaluated (Tab. 1). A nonionic surfactant with low HLB (sorbitan monooleate) was dosed for a better emulsion homogeneity, for interfacial tension control and to diminish droplet coalescence probability. An experimental planning was performed in two levels for each parameter (viscosity 12 and $26 \mathrm{mPas}$, interfacial tension 15 and $25 \mathrm{mN} / \mathrm{m}, \Delta \mathrm{P} 3$ and 9 bar, and dispersed phase concentrations $5 \%$ and $10 \%$ ). The mass flowrate was kept constant $(4 \mathrm{~kg} / \mathrm{min})$. Central points were added. The test matrix can be seen in Table 2 in Section 4 . Each experimental point was tested in a minimum of three replicates.

\subsection{Experimental bench}

A fluid pre-conditioning and pumping area was set up. It contained a water tank (200 L), oil tank (500 L) and progressive cavity pumps (all pumps installed with Variable Speed Drives - VSD). Downstream the pumps, Coriolis flowmeters and electrical heaters (aiming temperature, and consequently, viscosity control) were installed. This part of the experimental bench fed the test section where the water was injected in the oil stream in a T-junction. This commingle point was made with small orifices (diameter of $0.6 \mathrm{~mm}$ or $0.5 \mathrm{~mm}$ ) selected accordingly to water concentration in order to have high velocity in the injection point. The bench was constructed with carbon steel $1 / 2^{\prime \prime}$ pipes, sch40.

Downstream the T-junction, a mixing needle valve promotes an initial droplets break up generating the dispersion with the chosen average diameters (volumetric). This dispersion was pumped by a progressive cavity pump, to achieve the test pressure and flowrate, being ready to be sampled as inlet condition or go to the test section. After sampled the inlet condition, the flow was aligned to the test section, the experimental point was adjusted and, after stabilization, the outlet sample was collected. Figure 1 shows a simplified process and instrumentation diagram of the test bench.

\subsection{Test section singularity}

In the test section, a singularity (mimetic valve) was built and installed (Fig. 2). This dispositive is a channel with squared transversal section, with $5 \mathrm{~mm}$ side and $200 \mathrm{~mm}$ length. At inlet and outlet, a conical part was made so that pressure drops and recirculation zones could be avoided.

Internally, in the central part, three gates permit that a variety of geometric configurations could be tested. The gates have a micrometric position indicator in order to 
Table 2. Experimental results.

\begin{tabular}{lllllllll}
\hline & \multicolumn{7}{c}{ Conditions } & \multicolumn{5}{c}{ Mean values } & Std. deviation \\
\cline { 2 - 9 } & $\mu(\mathrm{mPa} \mathrm{s})$ & $\sigma(\mathrm{mN} / \mathrm{m})$ & $\Delta P($ bar $)$ & Conc. $(\%)$ & $d(0.9)(\mu \mathrm{m})$ & $d(0.9)(+/-)$ & $\varepsilon(\mathrm{W} / \mathrm{kg})$ & $\lambda_{\mathrm{K}}(\mu \mathrm{m})$ \\
\hline Point & & & & & & & & \\
1 & 12 & 25 & 3 & 5 & 67.6 & 8.6 & 84495 & 13.7 \\
2 & 12 & 25 & 9 & 5 & 43.4 & 5.3 & 261187 & 10.3 \\
3 & 12 & 25 & 3 & 10 & 100.5 & 11.7 & 84495 & 13.7 \\
4 & 12 & 25 & 9 & 10 & 65.3 & 9.8 & 261187 & 10.3 \\
5 & 26 & 25 & 3 & 5 & 67.1 & 0.7 & 84113 & 24.3 \\
6 & 26 & 25 & 9 & 5 & 37.6 & 7.2 & 260376 & 18.3 \\
7 & 26 & 25 & 3 & 10 & 74.3 & 5.8 & 84177 & 24.3 \\
8 & 26 & 25 & 9 & 10 & 49.1 & 0.8 & 260544 & 18.3 \\
$9 ; 10 ; 11$ & 19 & 20 & 6 & 7.5 & 48.4 & 5.3 & 172312 & 16.1 \\
12 & 12 & 15 & 3 & 5 & 59.9 & 6.8 & 84591 & 13.7 \\
13 & 12 & 15 & 9 & 5 & 39.4 & 5.0 & 261085 & 10.3 \\
14 & 12 & 15 & 3 & 10 & 90.2 & 4.9 & 84559 & 13.7 \\
15 & 12 & 15 & 9 & 10 & 64.0 & 12.9 & 261187 & 10.3 \\
16 & 26 & 15 & 3 & 5 & 63.5 & 6.4 & 83955 & 24.3 \\
17 & 26 & 15 & 9 & 5 & 40.9 & 13.5 & 260275 & 18.3 \\
18 & 26 & 15 & 3 & 10 & 71.4 & 6.4 & 84293 & 24.3 \\
19 & 26 & 15 & 9 & 10 & 37.2 & 0.3 & 260342 & 18.3 \\
\hline
\end{tabular}

know their exact position. The squared section was chosen for better discretization in numerical simulation studies.

By adjusting the position of the central gate, the flow through a gate valve could be simulated, with both superior gates kept fully opened. Other geometries can be simulated with this apparatus by changing the position of the other two gates position. Figure 3 shows details of the gate valve-like element, where $A$ is the squared section side, $L$ is the gate opening and $2.5 D_{\mathrm{h}}$ is the dissipation zone, correlated to the hydraulic diameter $\left(D_{\mathrm{h}}\right)$, defined as $D_{\mathrm{h}}=\frac{4 A}{P}$, where $\mathrm{P}$ is the wetted perimeter. This dissipation zone was applied for energy dissipation calculation.

The Droplet Size Distributions (DSD) were measured offline using a Malvern Mastersizer 2000. The sample point was located the nearest as possible of the test section in order to avoid coalescence. It was isolated by a ball valve which, when opened, gave full passage, avoiding droplet breakup possibility. Samples were collected and immediately diluted into beakers containing mineral oil, in order to avoid coalescence. Samples were gentle mixed with magnetic mixer and injected in Mastersizer by gravity in a regulated flowrate. All these procedures had the intention to preserve the experimental droplets representative without any possibility of droplet breakup or coalescence.

\section{Results and discussion}

When the gates were completely opened, the flow regime was set to be laminar. In this condition, the highest Reynolds number calculated for the lowest continuous phase viscosity was less than 1200. This limitation of
Reynold number had the objective of minimizing droplets break up due to pipe flow. Under these conditions, the inlet and outlet droplet size distributions were almost the same for the gates completely opened (Fig. 4).

Unlike what happens in pipes, where turbulent flow occurs in Reynolds $\left(\operatorname{Re}_{\mathrm{p}}\right)$ superior to 2100 , the critical Reynolds number for orifice $\left(\mathrm{Re}_{\mathrm{o}}\right)$ is smaller. Following Lakshmana Rao et al. (1977) and Janssen et al. (2001), the critical orifice Reynolds number in which the flow becomes turbulent, when passing through an orifice (quadrant-edged) with small $\beta=d_{\mathrm{o}} / D$, is constant and has values of 300-340, increasing with the increase of $\beta$, where $d_{\mathrm{o}}$ is orifice diameter and $D$ is the pipe diameter.

In a previous study, Johansen (1930) stated that the critical orifice Reynolds number could be even lower. The author observed on photographs that the flow started to become turbulent in Reynolds number above 150, depending on the diameter ratio, $\beta$.

Assuming that $\mathrm{Re}_{\mathrm{p}}=\beta \mathrm{Re}_{\mathrm{o}}$, and considering that the singularity can be compared to an orifice plate, theoretically in all experiment points the flow was laminar until reaching the singularity, where it became turbulent.

Table 2 shows the means of $d_{0.9} \sim d_{\max }$ of the experimental points results with its standard deviation. The mean energy dissipation rate $(e)$ and the Kolmogorov $\left(\lambda_{\mathrm{K}}\right)$ length scale were calculated using equations (12) and (13), respectively. Besides, the condition of each test point was stated. Table shows the viscosity $(\mu)$, interfacial tension $(\sigma)$, pressure drop across the apparatus $(\Delta \mathrm{P})$ and Concentration of water droplets in oil (Conc).

The experimental results are discussed separately. First, low concentration points $(5 \%$ of dispersed phase in 


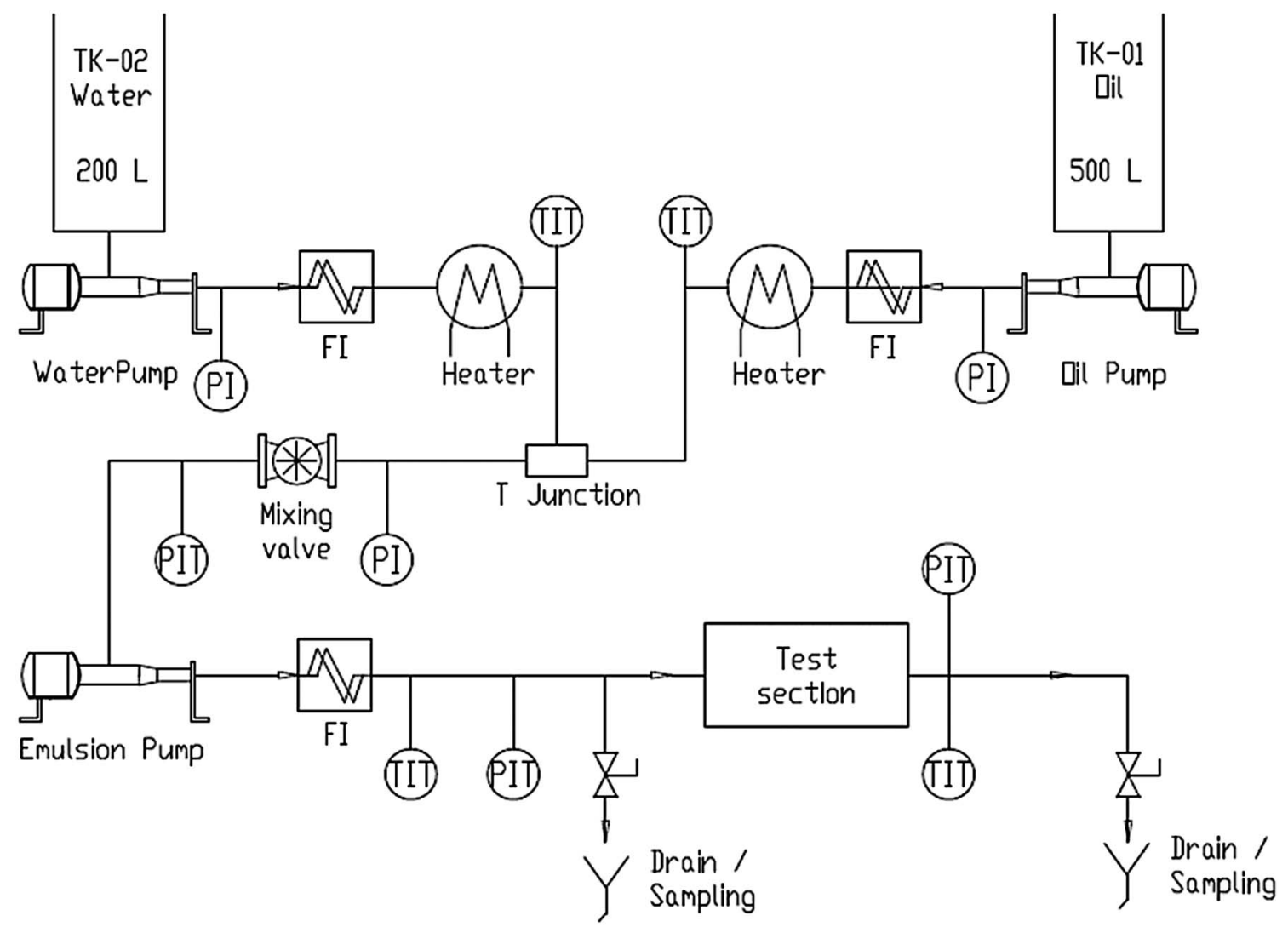

Fig. 1. Test bench simplified process and instrumentation diagram.

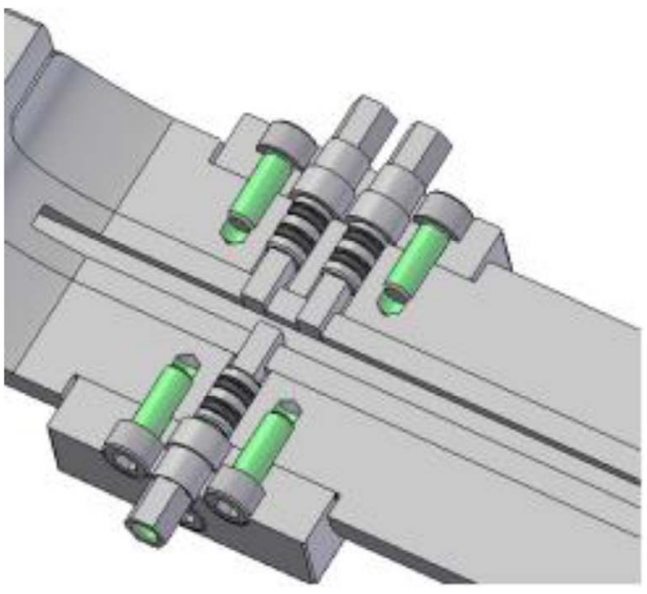

Fig. 2. Gate valve configuration.

oily continuous phase) together with the central point (concentration of $7.5 \%$ ) are analyzed. It was considered that $d_{0.9} \sim d_{\max }$ and that the turbulent energy dissipation (Eq. (12)) was calculated with the dissipation volume equivalent to the volume above of the gate plus the volume corresponding to the dissipation zone (Fig. 3), following van der Zande et al. (1999a) and Fossen and Schumann (2016).

The abovementioned experimental points means (with three replicates at least), separated by viscosity and

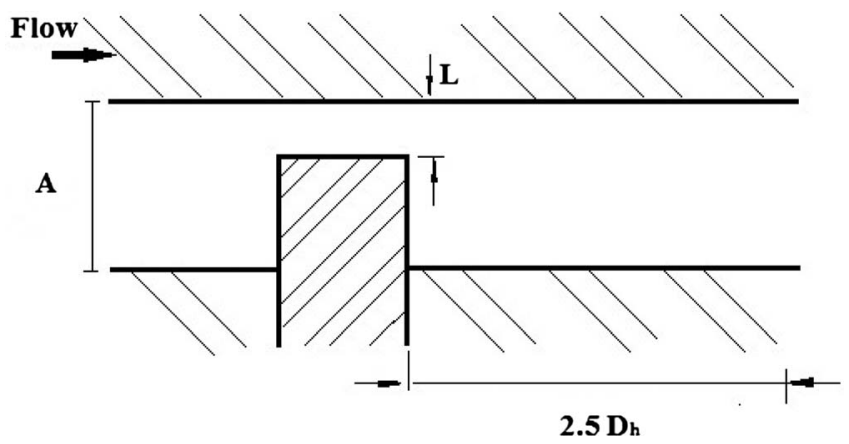

Fig. 3. Detail of gate valve configuration and dissipation zone.

interfacial tension levels, are shown in Figure 5. According to this figure, the continuous phase physical properties have no influence on the results. The Kolmogorov length scales curves for low and high viscosities are also presented in this figure.

Assuming that the larger eddy scale $\left(\lambda_{\max }\right)$ is equivalent to $0.1 D$ (Paolinelli and Yao, 2017), it is possible to say that $\lambda_{\mathrm{K}}<d_{\max }<\lambda_{\max }$ and, therefore, inertial break up models could be applied to the experimental results.

As can be seen in Figure 6, Hinze's model underestimates the experimental $d_{\max }$. This was also observed in other studies with higher continuous phase viscosity and 


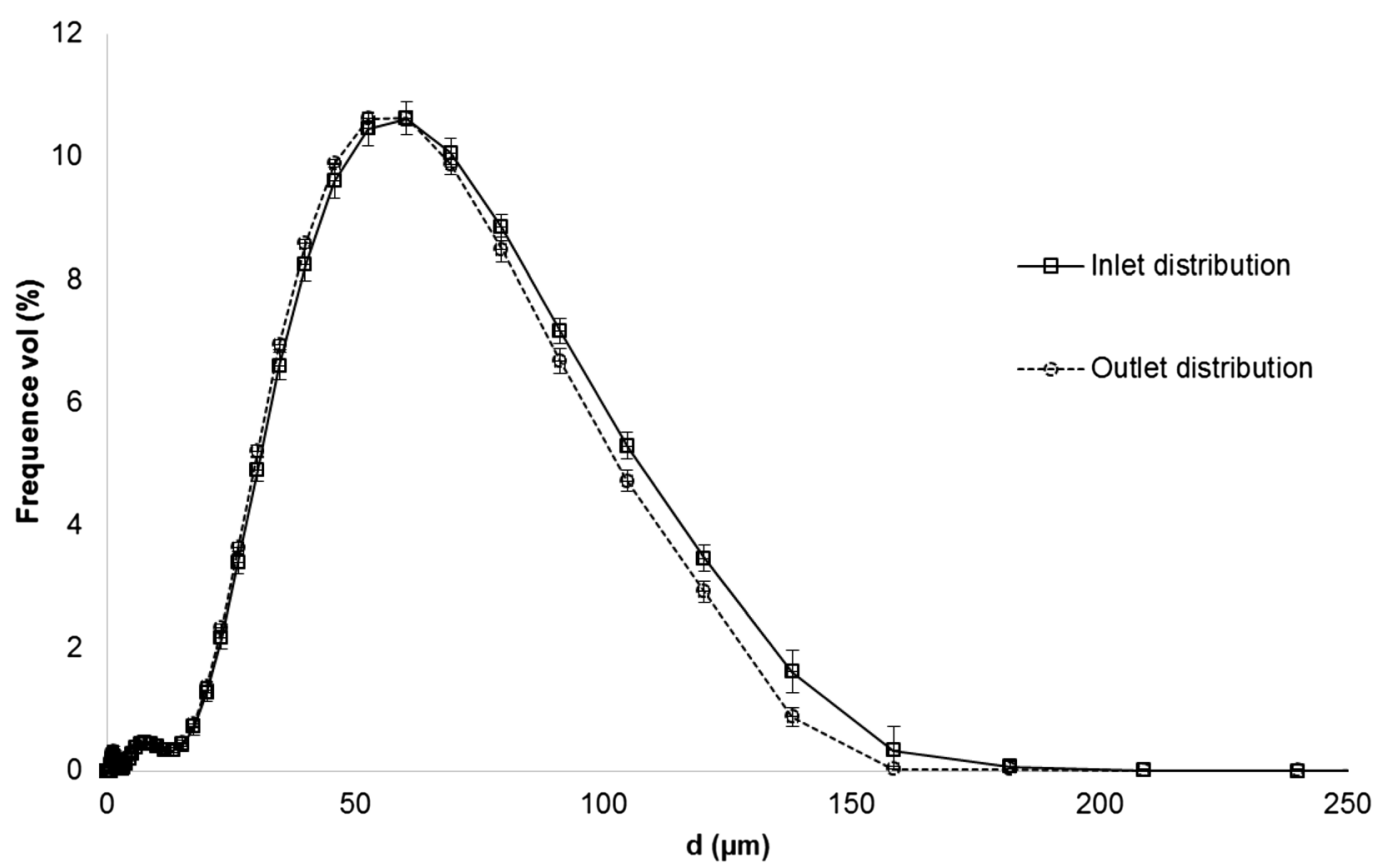

Fig. 4. Inlet and outlet droplet size distributions for the gate fully open $\left(\operatorname{Re}_{\mathrm{t}} \sim 1100\right)$.

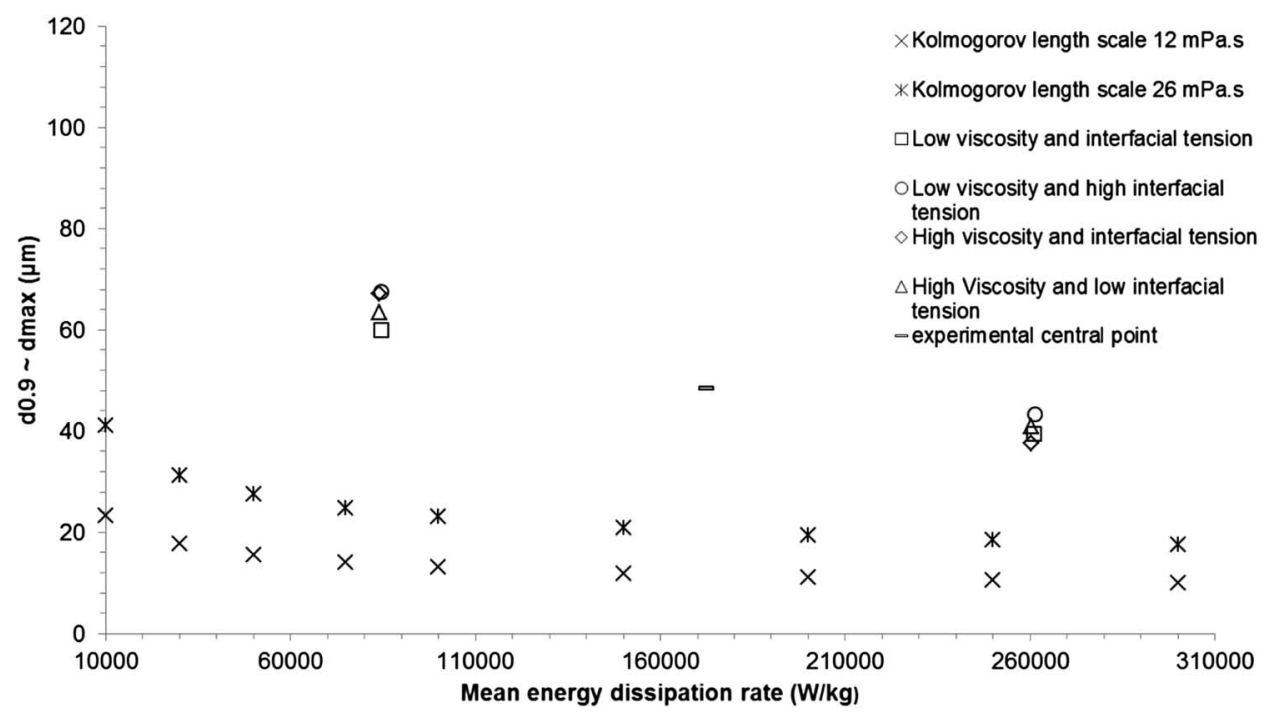

Fig. 5. Approximated maximum diameter $\left(d_{0.9} \cong d_{\max }\right)$ for experimental points at low concentrations $(5 \%$ and $7.5 \%)$.

with dispersed phase in higher concentration (Janssen et al., 2001; and Paolinelli and Yao, 2017).

Despite the fact that Hinze's model was not adequate to predict droplet size downstream the gate, it is important to notice that, according to the adjusted curve, the experimental $d_{\max } \propto \varepsilon^{-0.42}$ which is similar to Hinze's model where $d_{\max } \propto \varepsilon^{-0.4}$ (Eq. (9)).

Applying equation (9) to the experimental points at low concentrations ( $5 \%$ and $7.5 \%$ ), a constant of 3.2 is found, which is higher than Hinze's original constant of 0.725 .
The predicted curve using this new constant is also shown in Figure 6.

Considering the orifice droplet break up model proposed by Percy and Sleicher (1983) and applying the proportionality constant suggested by the authors of 3.1, this model also underestimates $d_{\max }$ and is only slightly better than Hinze's model. The calculation of $\Delta P_{\max }$ (therm of Percy and Sleicher model) was carried out following Paolinelli and Yao (2017), in which $\Delta P_{\max } \approx \Delta P_{\text {perm }} /\left(1-\beta^{2}\right)$, where $\beta$ is the ratio between hydraulic diameter of the gate 


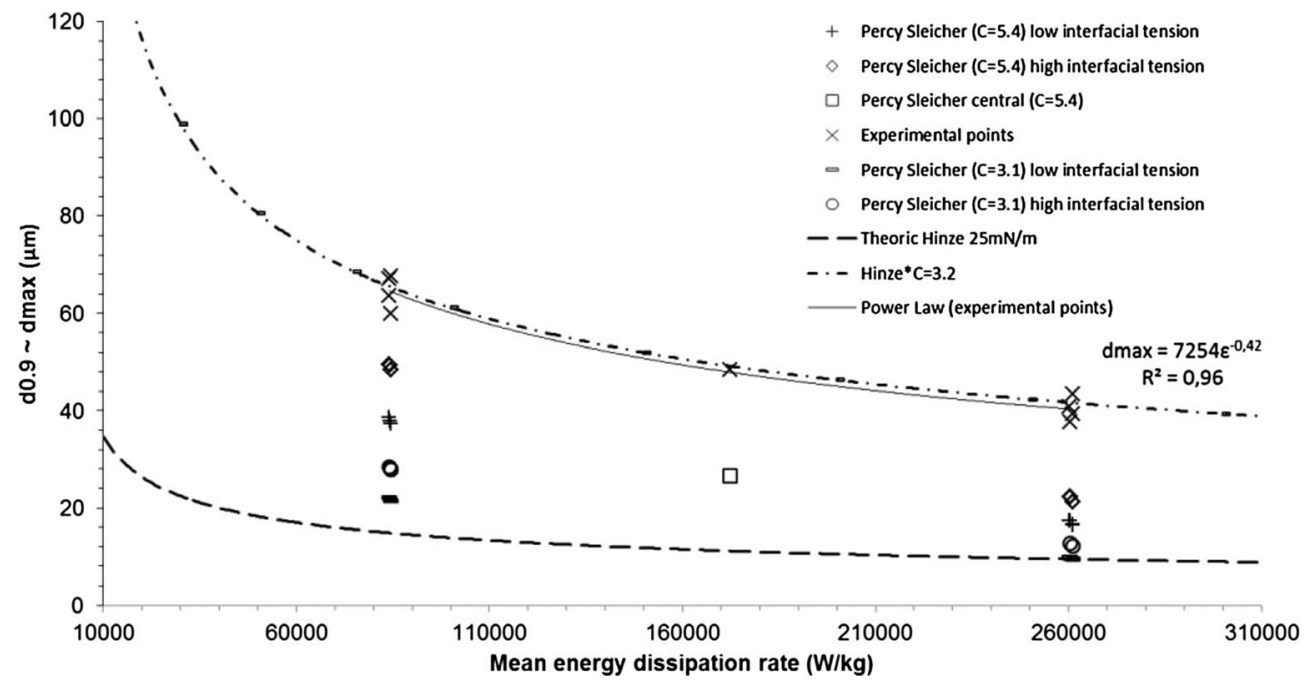

Fig. 6. A comparison between the experimental points for the approximated maximum diameter $\left(d_{0.9} \cong d_{\max }\right)$ at low concentrations $(5 \%$ and $7.5 \%)$ and different droplet break up models.

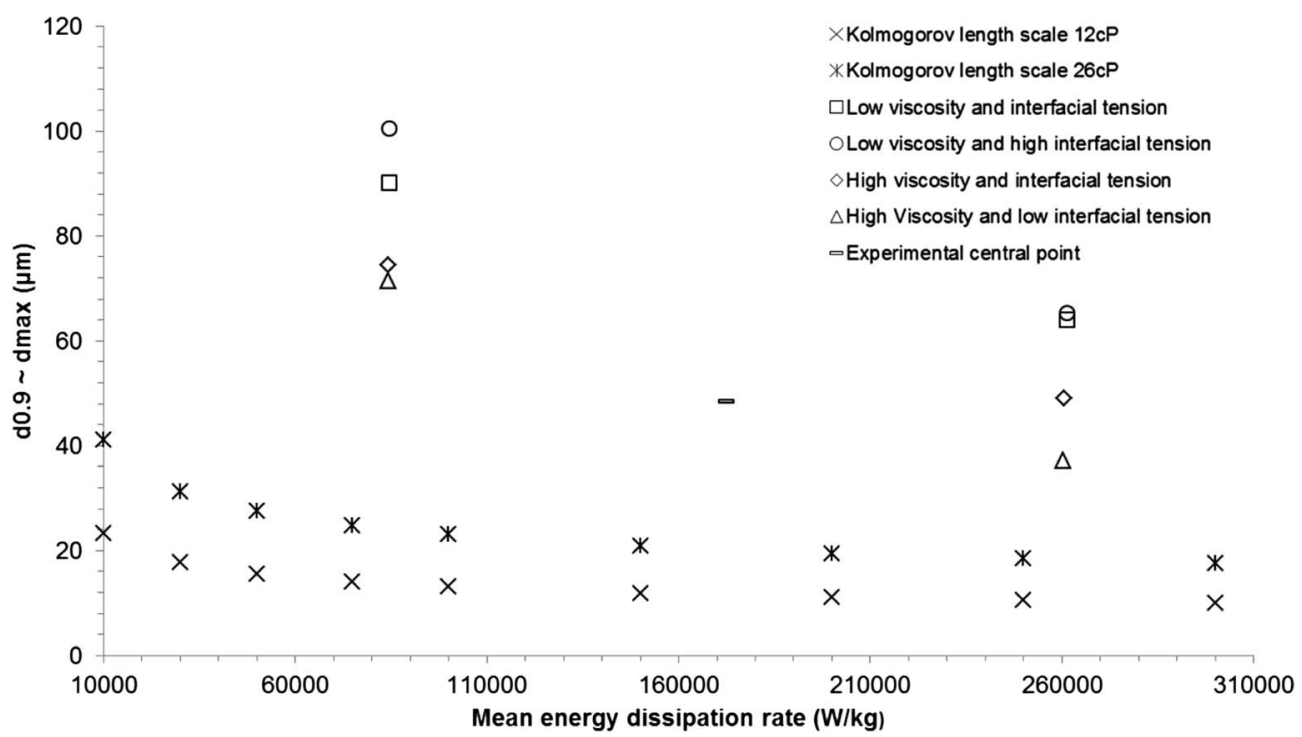

Fig. 7. Approximated maximum diameter $\left(d_{0.9} \cong d_{\max }\right)$ for experimental points at high concentration $(10 \%)$ and the central point $(7.5 \%)$.

opening and the hydraulic diameter of the channel. van der Zande and van den Broek (1998b) better fit their experimental points with $C=5.4$. By applying this constant value, fairly better predictions of $d_{\max }$ were obtained.

Figure 7 shows the results for the high dispersed phase concentration (10\%) adding the central point (7.5\%) for comparison. A higher dispersion of $d_{\max }$ is evident. As can be seen, points with lower viscosity presented higher maximum droplet size. The lower viscosity allied to higher concentration of droplets can make the dispersion more prone to coalescence effects (higher dispersed droplets interaction).
The increase of $d_{\max }$ due to higher dispersed phase concentration was also reported by Paolinelli and Yao (2017). They suggested that this increase in $d_{\max }$ was due to two phenomena. First, there is a turbulent tension effectiveness suppression, also called turbulence attenuation, due to an increase of emulsion apparent viscosity caused by the presence of higher content of dispersed droplet. The second phenomenon is due to coalescence that, at higher content, increases the probability of droplet collision (Walstra and Smulders, 1998).

It can be noted that at lower concentration the power law adjusted reasonably well the result for droplet break 


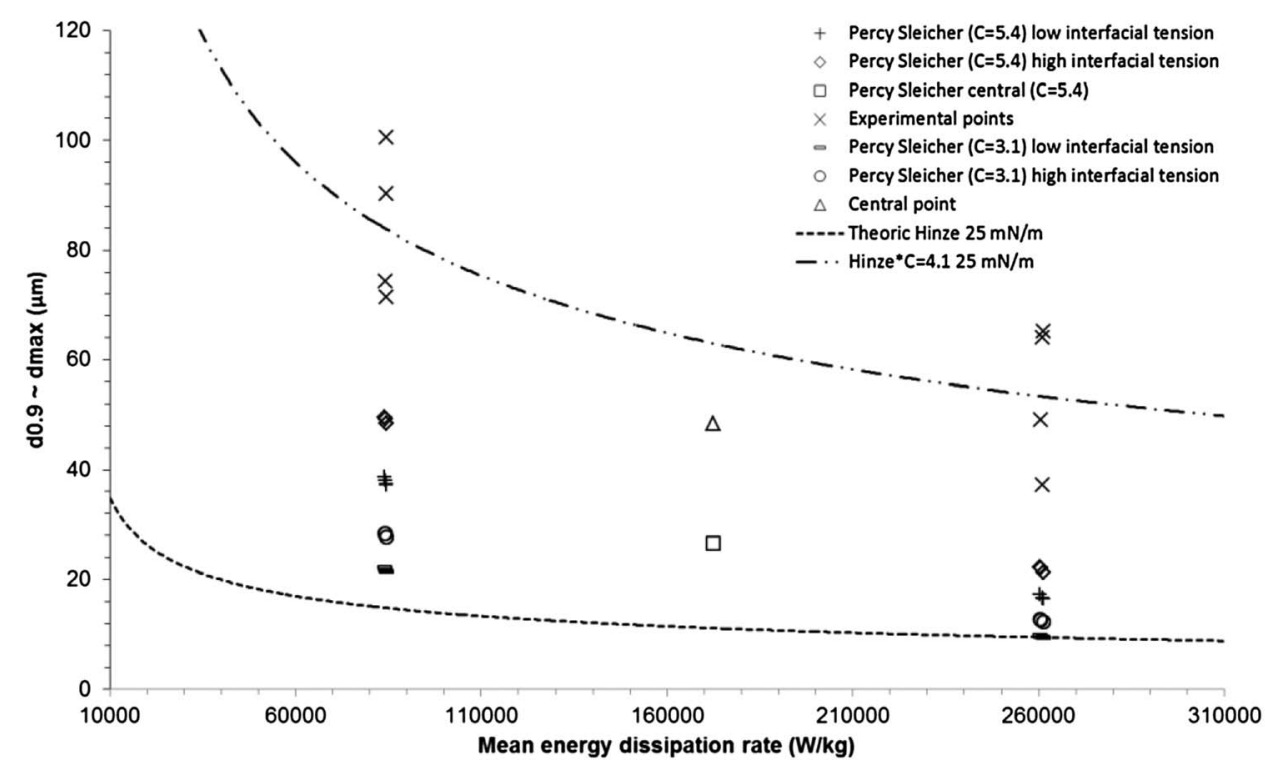

Fig. 8. A comparison between the experimental points for the approximated maximum diameter $\left(d_{0.9} \cong d_{\text {max }}\right)$ at high concentration $(10 \%)$ and different droplet break up models.

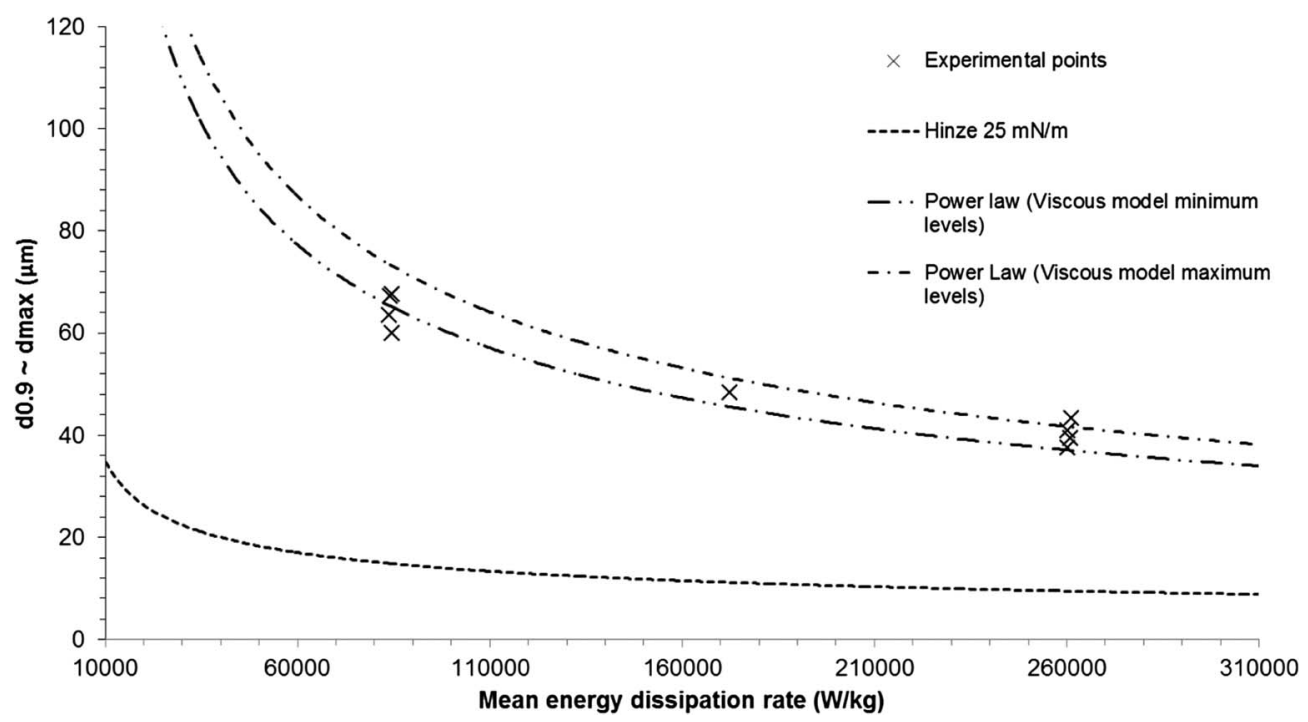

Fig. 9. Comparison of experimental $d_{\max }$ and curves predicted by the model proposed by Vankova et al. (2007) for low concentration $(5 \%)$.

up at the central point (Fig. 6). At high concentration, it was not possible to fit a single power law equation for the experimental points (Fig. 7). This suggests that the effects of turbulence suppression and/or coalescence just occur in concentrations above $7.5 \%$ of water dispersed in oil.

Figure 8 shows a comparison between the experimental points for the approximated maximum diameter $\left(d_{0.9} \cong d_{\max }\right)$ at high concentration $(10 \%)$ and different droplet break up models. In accordance with what was done previously, with the low concentration experimental points, a new constant for Hinze's model was tested. The best value for the constant was $C=4.1$. The curve of prediction considering the new constant to Hinze model is also shown in Figure 8.

Although all values of $d_{\max }$ are above Kolmogorov length scale (Figs. 5 and 7 ), the proximity to these values justified an evaluation of turbulent viscous droplet break up model. Figures 9 and 10 compare the experimental results of $d_{\max }$ with curves of prediction by the model proposed by Vankova et al. (2007) (Eq. (11)) for 5\% and 


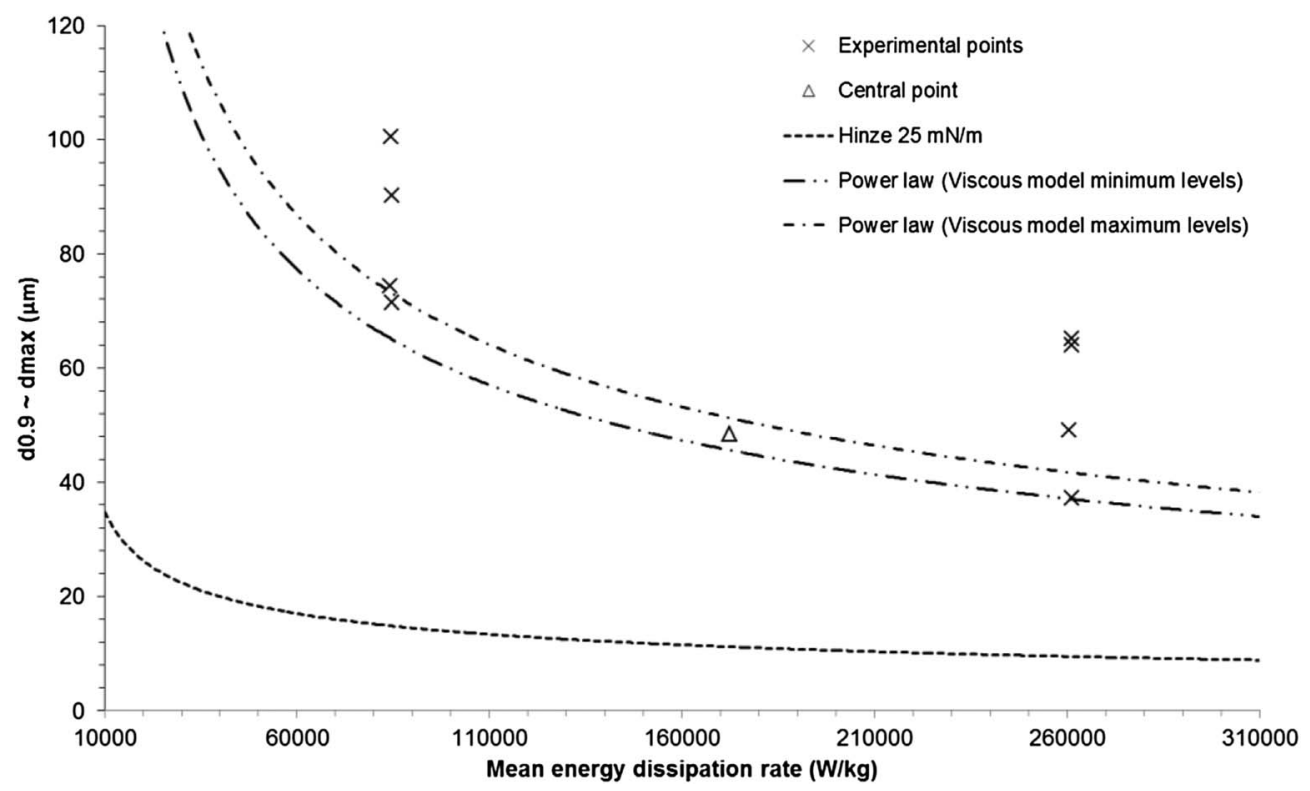

Fig. 10. Comparison of experimental $d_{\max }$ and curves predicted by the model proposed by Vankova et al. (2007) for high concentration $(10 \%)$.

$10 \%$ concentrations, respectively. Curves were calculated considering the lowest and highest levels for viscosity, interfacial tension and density.

From Figures 9 and 10, it can be observed that for low concentration the model proposed by Vankova et al. (2007) gives better results than for high concentration.

\section{Conclusion}

The experimental maximum droplet diameter decreased with increased turbulent energy dissipation rate according to a power law with a power of -0.42 for lower concentrations (less than 7.5\%). This power is similar to that of Hinze's model $(-0.4)$.

Increases in dispersed phase concentration increases the maximum diameters. Turbulence suppression, due to an increase of emulsion apparent viscosity, and/or coalescence, due to higher droplet population, can possibly explain it. Although lots of careful procedures adopted on sampling and measuring, some coalescence could have happened.

Hinze's inertial model was not capable to describe the experimental results. An increase in his proportionality constant tends to improve prediction. Percy and Sleicher model also was also not able to describe the results with the constant suggested by the authors. Applying the van der Zande and van den Broek (1998b) constant in Percy and Sleicher model gave slightly better results.

Although all experimental $d_{\max }$ were above Kolmogorov length scale, which would indicate that inertial forces are governing the phenomenon, turbulent viscous model described fairly well the experimental points. This may indicate that viscous forces may have some influence on the break up process.

New experiments will be performed to better understand which of the models (corrected turbulent inertial or turbulent viscous) is the most adequate to describe droplets break up phenomenon for a low viscous liquid dispersed in a more viscous continuous phase.

Acknowledgments. The authors would like to thank PETRO$B R A S$ and UNIFEI for their support for this study.

\section{References}

Angelli P., Hewitt G.F. (2000) Drop size distributions in horizontal oil-water dispersed flows, Chem. Eng. Sci. 55, 16, 3133-3143. https://doi.org/10.1016/S0009-2509(99)00585-0.

Arnold K., Stewart M. (1999) Arnold K., Stewart M., Surface production operations: design of oil-handling systems and facilities, Second Edition, Chapter 1, 2, Gulf Professional Publishing, ISBN 9780884158219. https://doi.org/10.1016/ B978-088415821-9/50002-6. http://www.sciencedirect.com/ science/article/pii/B9780884158219500026.

Batchelor G.K. (1951) Pressure fluctuations in isotropic turbulence, Math. Proc. Camb. Philos. Soc. 47, 2, 359-374. https://doi.org/10.1017/S0305004100026712.

Clay P.H. (1940a) The mechanism of emulsion formation in turbulent flow. I. Experimental Part, Proc. Roy. Acad. Sci. (Amsterdam) 43, 852.

Clay P.H. (1940b) The mechanism of emulsion formation in turbulent flow. II. Theoretical part and discussion, Proc. Roy. Acad. Sci. (Amsterdam) 43, 879.

Cristini V., Blawzdziewicz J., Loewenberg M., Collins L. (2003) Breakup in stochastic stokes flows: sub-Kolmogorov drops in isotropic turbulence, J. Fluid Mech. 492, 231-250. https://doi.org/10.1017/S0022112003005561.

Davies J.T. (1985) Drop sizes of emulsions related to turbulent energy dissipation rates, Chem. Eng. Sci. 40, 839-842. https://doi.org/10.1016/0009-2509(85)85036-3.

Fossen M., Schumann H. (2016) Experimental study of the relative effect of pressure drop and flow rate on the droplet size 
downstream a pipe restriction, J. Dispers. Sci. Technol. 38, 6, 826-831. https://doi.org/10.1080/01932691.2016.1207184.

Galinat S., Masbernat O., Guiraud P., Dalmazzone C., Noïk C. (2005) Drop break-up in turbulent pipe flow downstream of a restriction, Chem. Eng. Sci. 60, 23, 6511-6528. https://doi.org/10.1016/j.ces.2005.05.012.

Grace H.P. (1982) Dispersion phenomena in high viscosity immiscible fluid systems and application of static mixers as dispersion devices in such systems, Chem. Eng. Commun. 14, 225-277. https://doi.org/10.1080/00986448208911047.

Hinze J.O. (1955) Fundamentals of the hydrodynamic mechanism of splitting in dispersion process, AIChE J. 1, 3, 289-295. https://doi.org/10.1002/aic.690010303.

Husveg T., Bilstad T., Guinée P.G.A., Jernsletten J., Knudsen B., Nordbo H.T. (2009) A cyclone-based low shear valve for enhanced oil-water separation, Offshore Technology Conference, OTC 2009, https://doi.org/10.4043/20029-MS.

Janssen P.H., Noik C., Dalmazzone C. (2001) Emulsion formation in a model choke-valve, Society of Petroleum Engineers, SPE 71473. https://doi.org/10.2118/71473-MS

Johansen F.C. (1930) Flow through pipe orifices at low Reynolds numbers, Proc. R. Soc. Lond. A 126, 231-245. https://doi.org/ 10.1098/rspa.1930.0004. Published 1 January 1930.

Karbstein H., Schubert H. (1995) Developments in the continuous mechanical production of oil-in-water macro-emulsions, Chem. Eng. Process. Process. Intensification 34, 3, 205-211. https://doi.org/10.1016/0255-2701(94)04005-2.

Kubie J., Gardner G.C. (1977) Drop sizes and drop dispersion in straight horizontal tubes and in helical coils, Chem. Eng. Sci. 32, 195-202. https://doi.org/10.1016/0009-2509(77)80105-X.

Kwakernaak P.J., van den Broek W.M.G.T., Currie P.K. (2007) Reduction of oil droplet breakup in a choke, Society of Petroleum Engineers, SPE 106693. https://doi.org/10.2118/ 106693-MS.

Lakshmana Rao N.S., Sridharam K., Alvi S.H. (1977) Critical Reynolds number for orifice and nozzle flows in pipes, J. Hydraulic Res. 15, 2. https://doi.org/10.1080/ 00221687709499654.

Lemenand T., Della Valle D., Zellouf Y., Peerhossaini H. (2003) Droplets formation in turbulent mixing of two immiscible fluids in a new type of static mixer, Int. J. Multiph. Flow 29, 5, 813-840. https://doi.org/10.1016/S0301-9322(03)00032-6.

Lockhart F.J., Chilingarian G.V., Kumar S. (1987) Chapter 3 Separation of oil and Gas, in: G.V. Chilingarian, J.O. Robertson, S. Kumar (eds), Developments in Petroleum Science, vol. 19, Elsevier, pp. 59-108, ISSN 0376-7361, ISBN 9780444416254, https://doi.org/10.1016/S0376-7361(08)70532-6. http://www. sciencedirect.com/science/article/pii/S0376736108705326.

Manning F.S., Thompson R.E. (1995) Chapter 1, 2 and 6 - Oil field processing, Vol. 2, Pennwell Books, Crude Oil, ISBN 9780878143542 .

Mitre J.F., Lage P.L.C., Souza M.A., Silva E., Barca L.F., Moraes A.O.S., Coutinho R.C.C., Fonseca E.F. (2014) Droplet breakage and coalescence models for the flow of water-inoil emulsions through a valve-like element, Chem. Eng. Res. Des. J. 92, 2493-2508.

Paolinelli L.D., Yao A.R.J. (2017) Characterization of droplets sizes in large scale oil-water flow downstream from a globe valve, Int. J. Multiph. Flow 99, 132-150. https://doi.org/ 10.1016/j.ijmultiphaseflow.2017.09.014.

Percy J.S., Sleicher C.A. (1983) Drop breakup in the flow of immiscible liquids through an orifice in a pipe, AIChE J. 29, 1, 161-164. https://doi.org/10.1002/aic.690290125.
Rueger P.E., Calabrese R.V. (2013a) Dispersion of water into oil in a Rotor-Stator mixer. Part 1: drop breakup in dilute systems, Chem. Eng. Res. Des. 91, 2122-2133. https://doi.org/10.1016/ j.cherd.2013.05.018.

Rueger P.E., Calabrese R.V. (2013b) Dispersion of water into oil in a Rotor-stator Mixer. Part 2: Effect of phase fraction, Chem. Eng. Res. Des. 91, 2134-2141. https://doi.org/ 10.1016/j.cherd.2013.06.010.

Simmons M.J.H., Azzopardi B.J. (2001) Drop size distributions in dispersed liquid-liquid pipe flow, Int. J. Multiph. Flow 27, 5, 843-859. https://doi.org/10.1016/S0301-9322(00)00055-0.

Sleicher C.A. (1962) Maximum stable drop size in turbulent flow, AIChE J. 8, 4, 471-477. https://doi.org/10.1002/ aic. 690080410 .

Stone H.A. (1994) Dynamics of drop deformation and breakup in viscous fluids, Annu. Rev. Fluid Mech. 26, 65-102. https://doi.org/10.1146/annurev.fl.26.010194.000433.

Taylor G.I. (1932) The viscosity of a fluid containing small drops of another fluid, Proc. R. Soc. Lond. A 138, 41-48. Published 1 October 1932 https://doi.org/10.1098/rspa. 1932.0169.

Taylor G.I. (1934) The formation of emulsions in definable fields of flow, Proc. R. Soc. Lond. A 146, 501-523. Published 1 October 1934, https://doi.org/10.1098/rspa.1934.0169.

van der Zande M.J. (2000) Droplet break-up in turbulent oil-inwater flow through a restriction, PhD Thesis, ISBN 90-9013870-6.

van der Zande M.J., Muntinga J.H., van den Broek W.M.G.T. (1998a) Emulsification of production fluids in the choke valve, Society of Petroleum Engineers, SPE 49173. https://doi.org/ 10.2118/49173-MS.

van der Zande M.J., van den Broek W.M.G.T. (1998b) Breakup of oil droplets in the production system, Proc. of ASME Energy Sources Technology Conference and Exhibition, Houston, ETCE98-4744.

van der Zande M.J., van den Broek W.M.G.T. (1998c) The effect of tubing and choke valve on oil-droplet break-up, Proceedings of the 1st North American Conference on Multiphase Technology, June 10-11, Banff, Canada, pp. 89-100.

van der Zande M.J., van Heuven K.R., Muntinga J.H., van den Broek W.M.G.T. (1999a) Effect of flow through a choke valve on emulsion stability, Society of Petroleum Engineers, SPE 56640. https://doi.org/10.2118/56640-MS.

van der Zande M.J., Muntinga J.H., van den Broek W.M.G.T. (1999b) The effects of production rate and choke size on emulsion stability, Paper EXPL-6-MZ, presented at the 3rd International Seminar in Practices of Oil and Gas Exploitation, INGEPET 99, October 27-29, Lima, Peru.

Vankova N., Tcholakova S., Denkov N.D., Ivanov I.B., Vulchev V.D., Danner T. (2007) Emulsification in Turbulent flow 1. Mean and maximum drop diameters in inertial and viscous regimes, J. Colloid Interface Sci. 312, 363-380. https://doi.org/ 10.1016/j.jcis.2007.03.059.

Walstra P. (1983) Encyclopedia of emulsion technology, Vol. 1, Chapter 2, in: Becher P. (ed), Marcel Dekker, New York. ISBN-13: 978-0824718763, ISBN-10: 0824718763.

Walstra P. (1993) Principles of emulsion formation, Chem. Eng. Sci. 48, 2, 333-349. https://doi.org/10.1016/00092509(93)80021-H.

Walstra P., Smulders P.E.A. (1998) Modern aspects of emulsion science, Chapter 2, 1st edition (October 9, 1998), in: Binks B.P. (ed), Royal Society of Chemistry, UK, pp. 56-99. http:// dx.doi.org/10.1039/9781847551474-00056. 